\title{
Caregiver-reported delay in presentation to pediatric emergency departments for fear of contracting COVID-19: a multi-national cross-sectional study
}

\author{
Adrienne L. Davis ${ }^{1}$ (D) Alia Sunderji ${ }^{1}$. Shashidhar R. Marneni ${ }^{2} \cdot$ Michelle Seiler $^{3}$. Jeanine E. Hall ${ }^{4}$. \\ Cristina Parra Cotanda ${ }^{5}$. Eileen J. Klein ${ }^{6}$. Julie C. Brown ${ }^{6} \cdot$ Renana Gelernter $^{7} \cdot$ Mark A. Griffiths $^{8}$. Julia Hoeffe ${ }^{9}$. \\ Gianluca Gualco $^{10}$. Ahmed Mater ${ }^{11}$. Sergio Manzano ${ }^{12}$. Graham C. Thompson ${ }^{13}$. Sara Ahmed ${ }^{14}$. Samina Ali ${ }^{15}$. \\ Ran D. Goldman ${ }^{16}$. For the International COVID-19 Parental Attitude Study (COVIPAS) Group
}

Received: 15 December 2020 / Accepted: 28 June 2021 / Published online: 16 August 2021

(c) The Author(s), under exclusive licence to Canadian Association of Emergency Physicians (CAEP)/ Association Canadienne de Médecine d'Urgence (ACMU) 2021

\begin{abstract}
Objective To determine if caregivers of children presenting to pediatric emergency departments (EDs) during the COVID19 pandemic are delaying presenting to care for fear of contracting COVID-19.

Methods This was a pre-planned secondary analysis of a cross-sectional survey study of caregivers accompanying their children aged 0-19 years to 16 pediatric EDs in 5 countries from May to June 2020. An anonymous online survey, completed by caregivers via RedCAP, included caregiver and child demographics, presenting complaints, if they delayed presentation and whether symptoms worsened during this interval, as well as caregiver concern about the child or caregiver having COVID-19 at the time of ED visit.

Results Of 1543 caregivers completing the survey, 287 (18.6\%) reported a delay in seeking ED care due to concerns of contracting COVID-19 in the hospital. Of those, 124 (43.2\%) stated their child's symptoms worsened during the waiting interval. Caregiver relationship to child [mother] (OR 1.85, 95\% CI 1.27-2.76), presence of chronic illness in child (OR 1.78. 95\% CI 1.14-2.79), younger age of caregiver (OR 0.965, 95\% CI 0.943-0.986), and caregiver concerns about lost work during the pandemic (OR 1.08, 95\% CI 1.04-1.12) were independently associated with a COVID-19-related delayed presentation in multivariable regression analysis.

Conclusions Almost one in five caregivers reported delaying ED presentation for their ill or injured child specifically due to fear of contracting COVID-19 while in hospital, with mothers, younger caregivers, caregivers of children with chronic illness, and those concerned about lost work more likely to report delaying ED presentation.
\end{abstract}

Keywords COVID-19 $\cdot$ Presentation delay $\cdot$ Children $\cdot$ Caregivers $\cdot$ Emergency department

\section{Résumé}

Objectif Déterminer si les aidants des enfants qui se présentent aux services d'urgence pédiatriques (SU) pendant la pandémie de COVID-19 retardent leur présentation pour prendre soin d'eux par crainte de contracter la COVID-19.

Méthodes Il s'agissait d'une analyze secondaire planifiée à l'avance d'une étude d'enquête transversale auprès des soignants accompagnant leurs enfants âgés de 0 à 19 ans dans 16 urgences pédiatriques de 5 pays entre mai et juin 2020. Une enquête anonyme en ligne, remplie par les soignants via RedCAP, comprenait les données démographiques du soignant et de l'enfant, les plaintes présentées, s'ils ont retardé la présentation et si les symptômes se sont aggravés pendant cet intervalle, ainsi que l'inquiétude du soignant quant à la présence de COVID-19 chez l'enfant ou le soignant au moment de la visite aux urgences. Résultats Sur les 1543 soignants ayant répondu à l'enquête, 287 (18.6\%) ont déclaré avoir retardé le recours aux urgences par crainte de contracter le COVID-19 à l'hôpital. Parmi eux, 124 (43.2\%) ont déclaré que les symptômes de leur enfant

Adrienne L. Davis

adrienne.davis@sickkids.ca

Extended author information available on the last page of the article 
s'étaient aggravés pendant l'intervalle d'attente. Dans l'analyse de régression multivariable, le lien entre la personne qui s'occupe de l'enfant et la mère (OR 1.85, IC95 \% 1.27-2.76), la présence d'une maladie chronique chez l'enfant (OR 1.78, IC95 \% 1.14-2.79), le jeune âge de la personne qui s'occupe de l'enfant (OR 0.965, IC95\% 0.943-0.986) et les préoccupations de la personne qui s'occupe de l'enfant concernant la perte de travail pendant la pandémie (OR 1.08, IC95 \% 1.04-1.12) ont été associés de manière indépendante à une présentation tardive.

Conclusions Près d'un soignant sur cinq a déclaré avoir retardé la présentation aux urgences de son enfant malade ou blessé par crainte de contracter le COVID-19 pendant son séjour à l'hôpital, avec les mères, les jeunes aidants, les soignants d'enfants souffrant de maladies chroniques et les personnes préoccupées par la perte de travail sont plus susceptibles de retarder la présentation aux urgences.

\begin{tabular}{|l|}
\hline Clinician's capsule \\
What is known about the topic? \\
Visits to pediatric emergency departments (EDs) \\
decreased 75\% during COVID-19 with corresponding \\
increases in high acuity visits and admissions. \\
What did this study ask? \\
Are caregivers delaying presentation with their children \\
to the pediatric ED because of fear of contracting COVID- \\
19 in hospital? \\
What did this study find? \\
$\sim 20 \%$ of caregivers delayed pediatric ED presentation, \\
with younger age, fear of lost work, and children with \\
chronic illness associated with delay. \\
Why does this study matter to clinicians? \\
Messaging regarding the relative safety of attending the \\
pediatric ED is essential, and should be re-emphasized dur- \\
ing new pandemic waves.
\end{tabular}

\section{Introduction}

Fear in the community about the risk of contracting the novel coronavirus, SARS-CoV-2 (COVID-19), has been hypothesized as a cause for delayed presentation to the emergency department (ED) for children requiring acute care [1-4]. This concern stems from the combination of reduced volumes of presentations to EDs and Emergency Medical Services during the pandemic [3-5], as well as reports of increased complication rates and severity of disease for common pediatric conditions [1, 2, 6, 7]. Analysis of 18 EDs in British Columbia reported a reduction of $57 \%$ in overall visits to the children's hospital ED and $70 \%$ to 17 general hospital EDs [8]. An electronic survey completed by 2433 pediatric consultants in the United Kingdom and Ireland in April 2020 demonstrated that $32 \%$ of providers had witnessed delays in presentation [9]. In the 30 days following a national lockdown period, a US study found a significant decrease in mean daily number of pediatric ED visits accompanied by a corresponding increase in high acuity visits, and inpatient and ICU admissions compared to a historical cohort [3].

Although several studies have hypothesized that reduced ED visits and delayed presentation for non-COVID-19-related complaints may be due to fear of contracting COVID19 , no study to date has determined whether caregivers are consciously delaying presentation with their children to the ED. Understanding if caregivers are delaying presentation to the pediatric ED with their children, specifically for fear of contracting COVID-19, as well as characteristics of those choosing to delay, will aid hospitals and public health officials in developing targeted strategies to eliminate misconceptions and decrease morbidity related to delayed presentations for acute health conditions in children.

The primary objective of this study was to determine if caregivers of children $0-19$ years old presenting to the pediatric ED during the COVID-19 pandemic with nonCOVID-19-related concerns are delaying presentation for fear of contracting COVID-19 in the hospital. Secondary objectives were to (a) evaluate potential predictors of delay, (b) describe the proportion of children whose symptoms worsened during time to presentation, and (c) determine whether the proportion of children with reported delayed ED presentation varied over the duration of the study.

\section{Methods}

\section{Study design and setting}

This was a secondary data analysis of a multicenter, crosssectional survey of caregivers presenting to 16 pediatric EDs in the USA, Canada, Israel, Spain, and Switzerland [10-12].

\section{Survey development}

Modified Burns methodology was utilized for survey development and item reduction [13]. The study-specific items were developed by the COVID-19 Parental Attitude Study (COVIPAS) research team [10-12]. Major themes included demographics, presenting symptoms, whether ED presentation was delayed due to concern of catching COVID-19 and 
if symptoms worsened during this interval. We asked: "Did you decide to come to the Emergency Department later than you thought of coming initially — because you were worried about catching COVID in the hospital?" and, if yes, "Did your child's condition get worse between when you first thought of going to the Emergency Department and now?" We determined caregiver perception of the likelihood their child or themselves had COVID-19 at ED presentation on a 0-10 Likert scale. Literature related to the Severe Acute Respiratory Syndrome (SARS) epidemic in 2002-2003 helped inform questions in the survey. A group of $10 \mathrm{ED}$ healthcare providers provided feedback that led to revisions. All items of the survey were then piloted by ten caregivers not included in the final analysis and their feedback informed changes needed for face validity of the survey. The survey tool was translated and available in English, French, German, Spanish, Italian, and Hebrew.

\section{Population}

Figure 1 shows the inclusion of adult caregivers of children 0-19 years presenting to participating pediatric EDs with non-COVID-related concerns between May 4th and June 30th, 2020

Caregivers were excluded if their child had: (a) a known diagnosis of COVID-19; (b) possible symptoms of COVID19 (fever, sore throat, cough, congestion, shortness of breath, vomiting, and diarrhea) AND moderate-to-high caregiver suspicion that their child had COVID-19 (responded $\geq 3$ on a $0-10$ point Likert scale). We focused on non-COVID-related complaints, because (a) it is within this sphere that increased morbidity from suspected delayed presentation has been reported in children during the pandemic $[1,2,7]$, and (b) caregivers with moderate-to-high suspicion their child has COVID-19 may be less fearful of contracting it in the ED.

\section{Procedures}

Using posters placed in waiting areas and patient rooms, as well as direct approach by healthcare team members, caregivers were asked to take part in the survey. For infectious control purposes, caregivers used their own smartphones to complete the survey by logging into a secured online platform based on REDCap software (Vanderbilt University) [14]. Once a caregiver selected their study site, they provided consent for participation in the online survey, as approved by each site's local Institutional Review Board (IRB). Five IRBs (in Switzerland and Spain) provided a waiver of consent whereby responding to the survey was considered consent to participate. Only one caregiver completed the survey per visit.

\section{Data analysis}

Basic descriptive statistics and frequencies were used to describe all variables, using proportions for categorical data, means with standard deviations for the normally distributed continuous data and medians with inter-quartile ranges for continuous data lacking normal distribution. To determine which factors were significantly associated with delay in presentation, we used univariate logistic regression with the following a priori selected variables: child age, caregiver age, gender, caregiver education level, whether the child had a chronic illness, whether the child took any regular prescription meds, whether the chief complaint was related to injury/trauma, whether the caregiver was concerned about COVID-19 in themselves, whether the caregiver was concerned about lost income, and whether the child was fully immunized for standard childhood vaccinations. Given that multiple statistical tests were performed, to protect from type 1 error, a Bonferroni correction was used, adjusting alpha to 0.005 . We then used multivariable logistic regression analysis to evaluate independent predictors of delay, using all variables that showed $(p<0.2)$ in the univariate analysis as well as those deemed clinically plausible. All analyses were conducted with $\mathrm{R}$ version 3.5.1.

\section{Results}

Of the 1761 caregivers who completed the survey, 218 were excluded, because the children had symptoms associated with COVID-19 and moderate-to-high caregiver suspicion that their child had COVID ( $\geq 3$ on $0-10$ Likert scale), leaving 1543 available for analysis (see Fig. 1). Mean age of presenting caregivers was 39 (SD 8.1) years, 1121 (72.6\%) were mothers, $1163 / 1506(77.2 \%)$ completed greater than high school education, and median age of presenting child was 7.8 years (SD 5.1).

Two hundred eighty-seven (18.6\%) caregivers reported a delay in seeking ED care due to concerns of contracting COVID-19. Of those, 124 (43.2\%) stated symptoms worsened during the waiting interval prior to ED presentation. Trauma/injuries made up over $40.9 \%$ of study population, including musculoskeletal injuries, lacerations, burns, and head injuries. Gastrointestinal complaints including abdominal pain, vomiting, dehydration, GI bleed and IBD exacerbations, and suspected non-COVID-19-related infections (e.g., UTI, otitis media), including UTI, otitis, pharyngitis, abscess, and fever without a source, made up $12.9 \%$ and $12.5 \%$, respectively.

Table 1 describes the characteristics of patients and caregivers who delayed and did not delay presentation to the ED. 


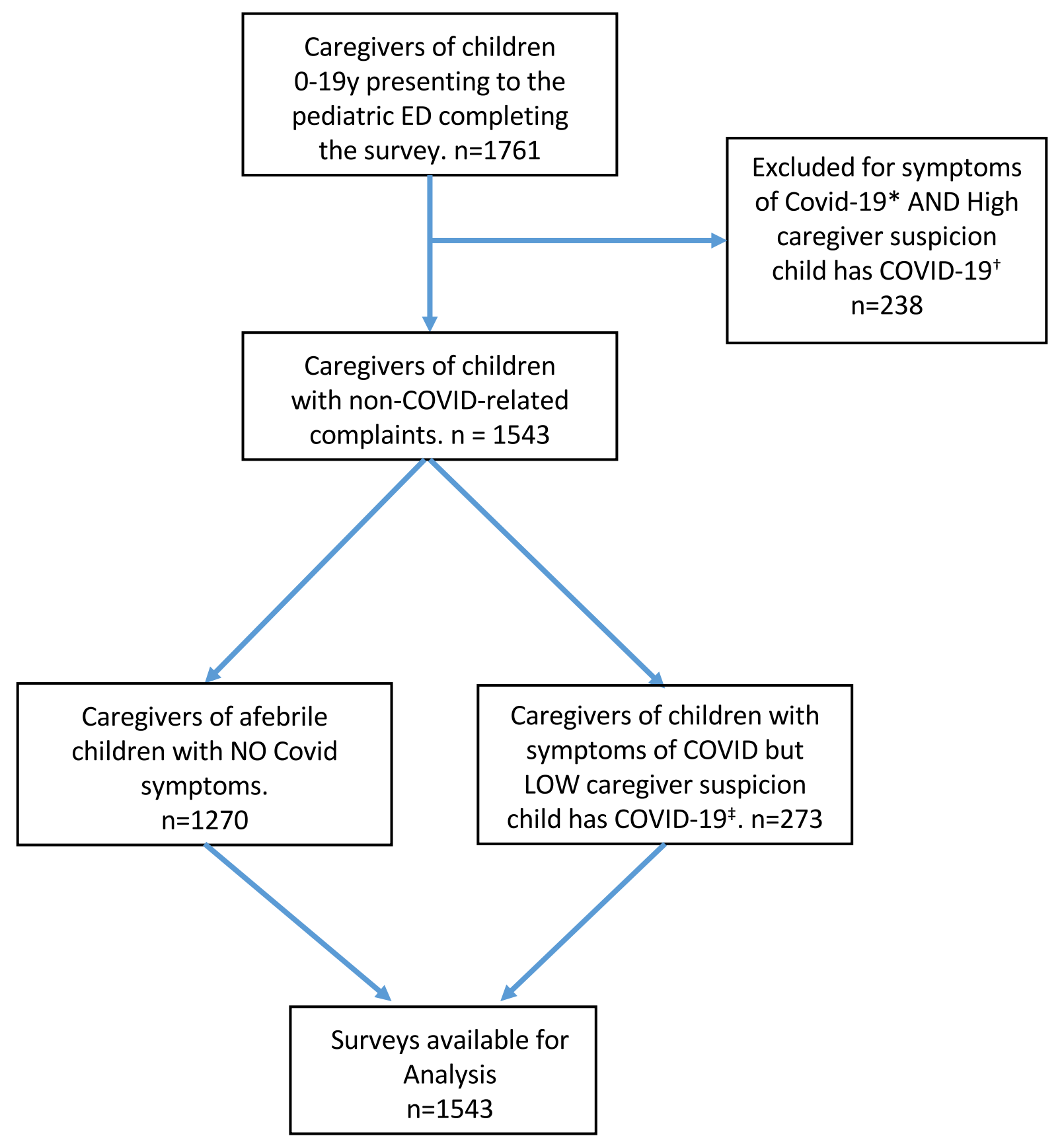

*Symptoms of COVID-19: fever, sore throat, cough, congestion, shortness of breath, vomiting, diarrhea

${ }^{+} H$ High caregiver suspicion of COVID-19 defined as $\geq 3$ on 10-point "Worry that your child has COVID" Likert scale

${ }^{\ddagger}$ Low caregiver suspicion of COVID-19 defined as $\leq 2$ on 10-point "Worry that your child has COVID" Likert scale

Fig. 1 Flow diagram of included and excluded study population 
Table 1 Characteristics of patients and caregivers with delayed and not delayed presentation

\begin{tabular}{|c|c|c|c|}
\hline & $\begin{array}{l}\text { Total } \\
n=1543\end{array}$ & $\begin{array}{l}\text { Not delayed } \\
n=1256\end{array}$ & $\begin{array}{l}\text { Delayed } \\
n=287\end{array}$ \\
\hline Patient age, years (mean, SD) & $7.8(5.10)$ & $7.8(5.12)$ & $7.7(5.2)$ \\
\hline Patient Gender Female (\%) & 47.7 & 47.8 & 47.4 \\
\hline \multicolumn{4}{|l|}{ Caregiver relationship } \\
\hline Mother $(\%)$ & 72.6 & 78.9 & 21.1 \\
\hline Father $(\%)$ & 23.8 & 88.9 & 10.6 \\
\hline Caregiver's age, years (SD) & $39.0(8.10)$ & $39.5(8.03)$ & $37.4(8.19)$ \\
\hline \multicolumn{4}{|l|}{ Caregiver education } \\
\hline More than high school (\%) & 75.4 & 76.8 & 79.1 \\
\hline Child has chronic illness (\%) & 12.6 & 11.5 & 18.6 \\
\hline \multicolumn{4}{|l|}{ Chief complaint } \\
\hline Trauma* $(\%)$ & 40.9 & 41.6 & 38.0 \\
\hline Gastrointestinal $^{\dagger}(\%)$ & 12.5 & 12.3 & 13.2 \\
\hline Non-COVID infection ${ }^{\S}(\%)$ & 12.9 & 12.7 & 13.6 \\
\hline No COVID-19 symptoms (\%) & 82.3 & 82.9 & 79.8 \\
\hline Child's immunizations are up-to-date (\%) & 89.4 & 89.2 & 90.2 \\
\hline History of Influenza vaccine, child (\% Yes) & 36.0 & 35.3 & 41.1 \\
\hline Worry about missed income (\%Yes) & 39.4 & 37.7 & 50.2 \\
\hline
\end{tabular}

$S D$ standard deviation; $*$ Trauma $=$ Musculoskeletal injuries, lacerations, burns, head injuries, foreign bodies; ${ }^{\dagger}$ Gastrointestinal = Abdominal pain, vomiting, diarrhea, Gastrointestinal bleed, constipation, dehydration, Inflammatory Bowel Disease flare, appendicitis; ${ }^{\S}$ Non-Covid Infection = ear infection, eye infection, UTI, pharyngitis
Table 2 Variables associated with reported delayed presentation to the pediatric emergency department in multivariable regression analysis

\begin{tabular}{lllc}
\hline Potential predictors of delay & Odds ratio & OR 95\% CI & $p$ value \\
\hline $\begin{array}{llll}\text { Caregiver } \\
\text { Age }\end{array}$ & 0.965 & $(0.943-0.986)$ & $\mathbf{0 . 0 0 1}$ \\
$\quad \begin{array}{l}\text { Relationship to child } \\
\quad \text { Mother) }\end{array}$ & 1.85 & $(1.27-2.76)$ & $\mathbf{0 . 0 0 2}$ \\
$\quad$ Worry lost work $\dagger$ & 1.08 & $(1.04-1.12)$ & $\mathbf{< 0 . 0 0 1}$ \\
$\quad$ Higher Education* & 0.71 & $(0.48-1.01)$ & 0.064 \\
Child & & & \\
$\quad$ Chronic illness & 1.78 & $(1.14-2.79)$ & $\mathbf{0 . 0 0 2}$ \\
$\quad$ Chronic medications & 0.91 & $(0.586-1.4)$ & 0.68 \\
$\quad$ Traumatic chief complaint & 0.981 & $(0.73-1.31)$ & 0.90 \\
$\quad$ Vaccinations Up-To-Date & 1.11 & $(0.69-1.86)$ & 0.69 \\
\hline
\end{tabular}

†'Worry about lost work= response to 0-10 Likert scale "How worried are you about missing work"

*Higher Education = greater than high school education $(\mathrm{Y} / \mathrm{N})$

In univariable regression analysis, the following variables were associated with reports of delayed presentation: presenting caregiver's relationship to child [mother] (OR2.27, 95\% CI 1.6-3.3), presence of chronic illness in the child (OR $1.75,95 \%$ CI 1.23-2.46), concerns about lost work during the pandemic (OR 1.08, 95\% CI 1.04-1.12), and age of caregiver (OR 0.97, 95\% CI 0.95-0.99).

Table 2 represents the multivariable regression for variables associated with delayed presentation. Presenting caregiver's relationship to child [mother] (OR 1.85, 95\% CI 1.27-2.76), presence of chronic illness in the child (OR 1.78. 95\% CI 1.14-2.79), age of caregiver (OR 0.965, 95\% CI 0.943-0.986), and concerns about lost work during the pandemic (OR 1.08, 95\% CI 1.04-1.12), remained independently associated with a COVID-19-related delayed presentation in multivariable regression analysis.

Figure 2 shows the rates of $a$. delay and $b$. worsening symptoms during the delayed period over time. A univariable linear regression of four, 2-week "study blocks" on rates of delay showed no statistical significance of one time point compared to another for rates of delayed presentation (OR 1.33, 95\% CI: $0.93-1.90, p=0.381$ ), or for worsening symptoms during the period of delay (OR 1.73, 95\% CI: 1.03-2.93, $p=0.158$ ).

\section{Discussion}

\section{Interpretation of findings}

Our study found that in an international cohort of caregivers presenting to 16 pediatric EDs from May to June 2020, 
Fig. 2 Rates of delayed presentation to the emergency department over time

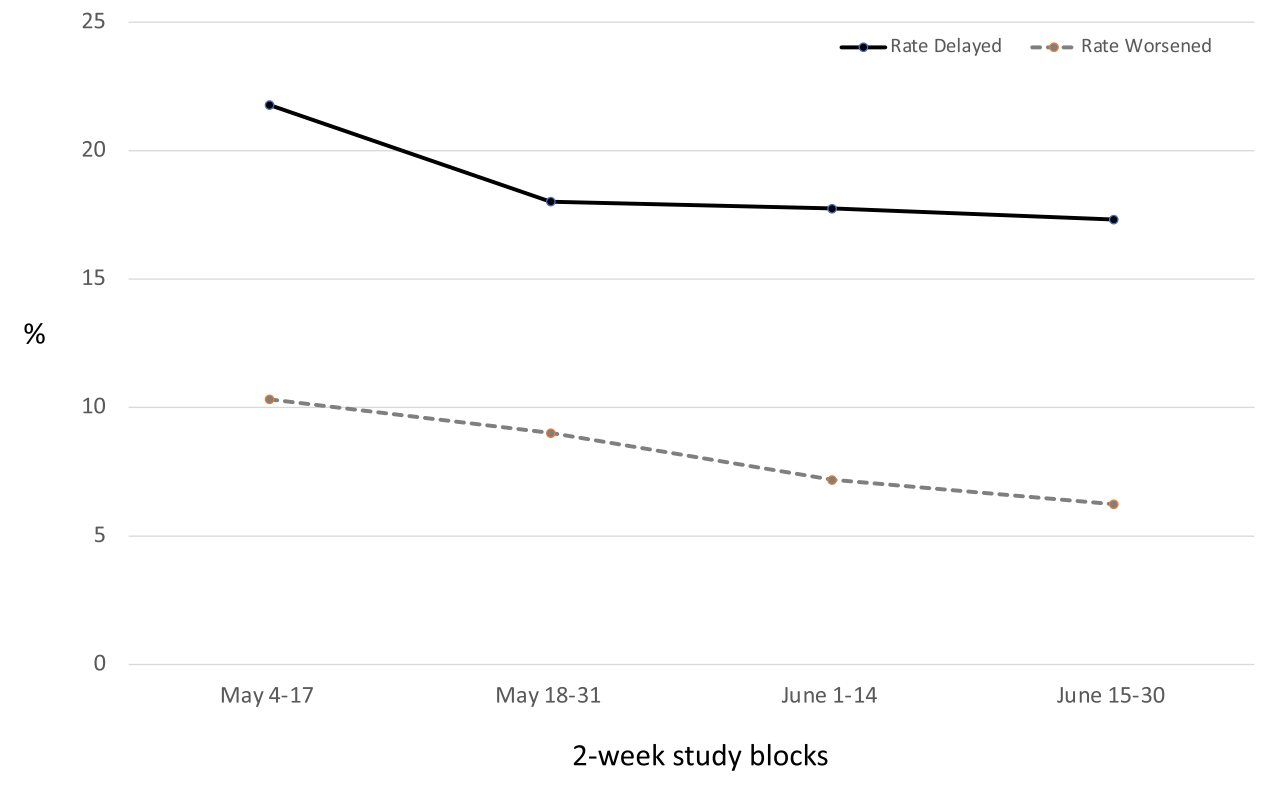

nearly one in five reported delaying presentation specifically due to concerns of contracting COVID-19 in the hospital. Of those who delayed, almost half (43\%) felt their child's symptoms worsened during the waiting interval prior to ED presentation. Younger age of caregivers, when mothers were the presenting caregiver, caregivers of children with chronic illnesses, and overall fear of lost work during the pandemic were independently associated with delayed presentation. Caregivers of children with chronic illnesses in our cohort might have delayed ED presentation because of perceived or actual increased risk of their child developing severe disease from COVID-19 [15]. Additionally, caregivers of children with chronic illness may be more experienced and accustomed to caring for an unwell child at home, and feel better prepared to watch and wait before seeking emergency care. Similarly, older caregivers may have more experience weighing risk and determining appropriateness of urgent visits. In a study of 100 mothers examining predictors of decisions to seek urgent medical care for their children, delay in seeking treatment was associated with experience, with older caregivers of older children bringing children to urgent care with minimal delay [16]. Our findings also highlight the increased risk of delayed presentation for those fearing job loss during the pandemic. Fear of job loss is likely to be more prevalent among caregivers with low-paying jobs which cannot be done remotely, and among caregivers with precarious employment (part-time and informal workers) [17-19]. Policy measures enacted to protect the jobs of absent workers caring for their ill or injured children $[20,21]$ may fall short from easing caregiver anxiety, either because caregivers were unaware of the policies or because they remain fearful they will not truly be protected from job loss or lost wages.

\section{Comparison to previous studies}

These results corroborate a US COVID-19 survey of 5412 adults which asked "Have you delayed or avoided medical care due to concerns related to COVID-19"? [22]. Twelve percent of respondents delayed or avoided urgent or emergency care. Delay was significantly higher among unpaid caregivers for adults (OR 2.9; 95\% CI 2.3-3.6); people with $\geq$ two underlying medical conditions (OR 1.9; $95 \% \mathrm{CI}$ 1.5-2.4); and those 18-24 years of age (versus $25-44$ years) (OR 1.5; 95\% CI 1.2-1.8) [22].

Fear of virus transmission while utilizing healthcare resources during an epidemic is not new. During SARS in 2003, a Taiwanese study showed significant healthcare utilization reductions and considered SARS fear significantly influencing people's care-seeking behavior [23]. Fearrelated avoidance of healthcare facilities may be shaped by the healthcare response and public trust established early in epidemics [24]. A qualitative study conducted during the Ebola outbreak found that widespread deaths and limited healthcare capacity reported early in the outbreak strongly influenced participants' reluctance to access care later, despite improved surveillance and treatment capacity [25].

\section{Clinical Implications}

Delay in seeking care can lead to increased morbidity and mortality [26-28]. An Italian case series of 12 pediatric patients with delayed access to hospital care during the pandemic indicated progression of disease during the delay, resulting in six pediatric intensive-care unit (PICU) admissions and four deaths [6]. An American case series of five children with leukemia highlighted an unprecedented gap of 
35 days between new leukemia diagnoses during the pandemic, over 11 times higher than the mean 5-year average. This study also reported a six-fold increase in PICU admissions associated with new leukemia diagnoses, compared to historical pre-pandemic average [7]. A study of 532 children and adolescents with newly diagnosed type 1 diabetes found a 1.4-fold increase in rate of diabetic ketoacidosis [1]. Furthermore, an Israeli case series of children with appendicitis reported a twofold increase in complication rate during the pandemic, compared to prior experience [2]. Similarly, a US single-center study found a $20 \%$ increase in rates of perforated appendicitis in children during the pandemic compared to an historical cohort [29].

\section{Research implications}

These findings highlight a key insight from risk communication in disasters: the public perception of a threat is equally as dangerous as the threat itself [30]. Perception of risk, as noted by the Center for Disease Control, is "tied to the degree to which persons feel alarmed or outraged", and perceived risks to child health in particular are noted to be inherently less acceptable [24]. Garnering the trust of the public is critical in public health responses in pandemics. Risk communications is an established methodology of communicating honestly and effectively the risks associated with natural hazards and human activities [31]. Analysis of over 1000 studies worldwide by the United Kingdom's Department of Health resulted in publication of valuable risk communication strategies, including openness, transparency, demonstrating action and progress, treating people's fears seriously, framing announcements and responses to provide context, and encouraging and enabling self-responsibility [32]. Early in the pandemic, most messaging focused on social distancing, hand hygiene, personal protective equipment, need for augmented testing, and staying home [33]. Less well communicated was the work hospitals were doing to keep people safe, including universal masking, frequent cleaning and disinfecting, screening at all entrances, separate waiting areas for people with and without COVID-19 symptoms, and maintaining social distancing. Effectively communicating these measures through social media, digital press kits for the news media, call centers, and virtual town halls for clinicians may help calibrate the public perception of risk [24]. Caregivers should also be made fully aware of the risks of delayed presentation for emergency conditions. Although several news articles have specifically addressed this issue [34, 35], the message is not reaching its intended target. We found that rates of delay were not statistically different across the eight week study period, despite various efforts in the media to encourage caregivers to attend the pediatric ED when needed $[36,37]$. As new virtual care models are being developed, we may have an opportunity to provide education to families regarding the relative safety to presenting to the ED when providing anticipatory guidance. Future research should examine the best implementation strategies for communicating this message to caregivers.

\section{Limitations}

Our study has several limitations. First, the population of caregivers responding to the survey does not represent all caregivers in the sites where the study was conducted, as only a subset of families (likely $<5 \%$ of visitors to 16 pediatric EDs) filled out the survey. We also relied on caregiver possession of a smartphone/tablet/computer to complete the survey online, which may have limited some caregivers from responding. As this was an anonymous survey conducted in the absence of onsite research teams at the start of the pandemic, we relied on the accuracy of caregiver responses to the status of delay and could not correlate responses with the presence of deleterious or preventable medical outcome. Thirdly, the survey did not explore other pandemic-related barriers contributing to delays in seeking care, such as transportation, childcare, restrictions in number of caregivers allowed entry into the ED, or limited access to primary care providers. Additionally, the survey did not assess baseline patterns of delay in care-seeking or timing or duration of care avoidance. Finally, the survey did not examine caregiver perceptions around factors influencing risk of exposure. Further research should explore caregiver knowledge about risk-minimizing hospital activities, misconceptions around exposure to better guide public health messaging, as well as the association between caregiver-reported delayed presentation and patient morbidity/mortality.

\section{Conclusion}

In an international sample of caregivers presenting to pediatric EDs for non-COVID-19-related complaints from May-June 2020, nearly 1 in 5 reported a delay in seeking care specifically from fear of contracting COVID-19. Better messaging regarding the relative safety of attending the pediatric emergency department is urgently needed. Caregivers should be aware of potential dangers of keeping ill or injured children at home. Our findings can guide hospital and public health risk communication toward younger caregivers and those with children with chronic conditions who were more likely to delay their ED presentation due to fear. Caregivers who feared job loss were also more likely to delay seeking emergent care for their children and support the need for continued policies that protect caregivers from job loss while seeking medical attention. 
Supplementary Information The online version contains supplementary material available at https://doi.org/10.1007/s43678-021-00174-z.

Acknowledgements The study team would like to thank Prasra G. Olson, MD, MS, Marina Armendariz, MD, and Sofronia M. Ringold, BA, from Children's Hospital Los Angeles, and Bethany Lerman, BA, from Hospital for Sick Children for their support in recruiting patients and the conduct of the study.

Funding This research did not receive any specific grant from funding agencies in the public, commercial, or not-for-profit sectors. All authors had full access to all of the data (statistical reports and tables) in the study and can take responsibility for the integrity of the data and the accuracy of the data analysis.

\section{References}

1. Kamrath C, Mönkemöller K, Biester T, Rohrer TR, Warncke K, Hammersen J, Holl RW. Ketoacidosis in children and adolescents with newly diagnosed type 1 diabetes during the COVID-19 pandemic in Germany. JAMA. 2020;324(8):801-4.

2. Snapiri O, Rosenberg Danziger C, Krause I, Kravarusic D, Yulevich A, Balla U, Bilavsky E. Delayed diagnosis of pediatric appendicitis during the COVID-19 pandemic. Acta Paediatrica. 2020;109(8):1672-1676

3. Chaiyachati BH, Agawu A, Zorc JJ, Balamuth F. Trends in pediatric emergency department utilization after Institution of COVID19 mandatory social distancing. J Pediatr. 2020;226:274-277

4. Ciacchini B, Tonioli F, Marciano C, Faticato MG, Borali E, Prato AP, Felici E. Reluctance to seek pediatric care during the COVID19 pandemic and the risks of delayed diagnosis. Ital J Pediatr. 2020;46(1):1-4.

5. Kenyon CC, Hill DA, Henrickson SE, Bryant-Stephens TC, Zorc JJ. Initial effects of the COVID-19 pandemic on pediatric asthma emergency department utilization. J Allergy Clin Immunol. 2020;8(8):2774-6.

6. Lazzerini M, Barbi E, Apicella A, Marchetti F, Cardinale F, Trobia G. Delayed access or provision of care in Italy resulting from fear of COVID-19. Lancet Child Adolesc Health. 2020;4(5):e10-1.

7. Ding YY, Ramakrishna S, Long AH, Phillips CA, Montiel-Esparza R, Diorio CJ, Bailey LC, Maude SL, Aplenc R, Batra V, Reilly AF. Delayed cancer diagnoses and high mortality in children during the COVID-19 pandemic. Pediatric Blood Cancer. 2020;67(9):e28427

8. Goldman RD, Grafstein E, Barclay N, Irvine MA, Portales-Casamar E. Paediatric patients seen in 18 emergency departments during the COVID-19 pandemic. Emerg Med J. 2020;37(12):773-7.

9. Lynn RM, Avis JL, Lenton S, Amin-Chowdhury Z, Ladhani SN. Delayed access to care and late presentations in children during the COVID-19 pandemic: a snapshot survey of 4075 paediatricians in the UK and Ireland. Arch Dis Childhood. 2020;106(2) 1:e8-e8

10. Goldman RD, Marneni SR, Seiler M, Brown JC, Klein EJ, Cotanda CP, Gelernter R, Yan TD, Hoeffe J, Davis AL, Griffiths MA. Caregivers' willingness to accept expedited vaccine research during the COVID-19 pandemic: a cross-sectional survey. Clin Therapeutics. 2020;42(11):2124-2133

11. Goldman RD, McGregor S, Marneni SR, Katsuta T, Griffiths MA, Hall JE, Seiler M, Klein EJ, Cotanda CP, Gelernter R, Hoeffe J. Willingness to vaccinate children against influenza after the Coronavirus disease 2019 pandemic. J Pediatrics. 2020;228:87-93

12. Goldman RD, Yan TD, Seiler M, Cotanda CP, Brown JC, Klein EJ, Hoeffe J, Gelernter R, Hall JE, Davis AL, Griffiths MA.
Caregiver willingness to vaccinate their children against COVID19: cross sectional survey. Vaccine. 2020;38(48):7668-73.

13. Burns KE, Duffett M, Kho ME, Meade MO, Adhikari NK, Sinuff T, Cook DJ. A guide for the design and conduct of self-administered surveys of clinicians. CMAJ. 2008;179(3):245-52.

14. Harris PA, Taylor R, Thielke R, Payne J, Gonzalez N, Conde JG. Research electronic data capture (REDCap) - a metadata-driven methodology and workflow process for providing translational research informatics support. J Biomed Inform. 2009;42(2):377-81.

15. Ademhan Tural D, Emiralioglu N, Tural Hesapcioglu S, Karahan S, Ozsezen B, Sunman B, Nayir Buyuksahin H, Yalcin E, Dogru D, Ozcelik U, Kiper N. Psychiatric and general health effects of COVID-19 pandemic on children with chronic lung disease and parents' coping styles. Pediatric Pulmonol. 2020; 55(12):3579-3586

16. Turk DC, Litt MD, Salovey P, Walker J. Seeking urgent pediatric treatment: factors contributing to frequency, delay, and appropriateness. Health Psychol. 1985;4(1):43.

17. Blumenshine P, Reingold A, Egerter S, Mockenhaupt R, Braveman P, Marks J. Pandemic influenza planning in the United States from a health disparities perspective. Emerg Infect Dis. 2008;14(5):709.

18. Blustein DL, Guarino PA. Work and unemployment in the time of COVID-19: the existential experience of loss and fear. J Humanist Psychol. 2020;60(5):702-9.

19. Reichert AR, Augurzky B, Tauchmann H. Self-perceived job insecurity and the demand for medical rehabilitation: does fear of unemployment reduce health care utilization? Health Econ. 2015;24(1):8-25.

20. Ontario Supporting Workers, Municipalities and Retailers in Response to COVID-19. https://news.ontario.ca/en/release/ 56384/ontario-supporting-workers-municipalities-and-retailersin-response-to-covid-19. Published March 19, 2020. Accessed September 5th, 2020.

21. US Department of Labor. Families First Coronavirus Response Act: Employee Paid Leave Rights. 2020. https://www.dol.gov/ agencies/whd/pandemic/ffcra-employee-paid-leave. Accessed: Nov 7th, 2020.

22. Czeisler MÉ, Marynak K, Clarke KE, Salah Z, Shakya I, Thierry JM, Ali N, McMillan H, Wiley JF, Weaver MD, Czeisler CA. Delay or avoidance of medical care because of COVID-19related concerns-United States, June 2020. Morb Mortal Wkly Rep. 2020;69(36):1250.

23. Chang HJ, Huang N, Lee CH, Hsu YJ, Hsieh CJ, Chou YJ. The impact of the SARS epidemic on the utilization of medical services: SARS and the fear of SARS. Am J Public Health. 2004;94(4):562-4.

24. Tumpey AJ, Daigle D, Nowak G. Communicating during an outbreak or public health investigation. CDC, Epidemic Intelligence Service. (accessed on 30 January 2020). 2018.

25. Yamanis T, Nolan E, Shepler S. Fears and misperceptions of the Ebola response system during the 2014-2015 outbreak in Sierra Leone. PLoS Negl Trop Dis. 2016;10(10):e0005077.

26. Kamp J. Death toll from covid-19 pandemic extends far beyond virus victims. The Wall Street J. 2020.

27. Chanchlani N, Buchanan F, Gill PJ. Addressing the indirect effects of COVID-19 on the health of children and young people. CMAJ. 2020;192(32):E921-7.

28. Barach P, Fisher SD, Adams MJ, Burstein GR, Brophy PD, Kuo DZ, Lipshultz SE. Disruption of healthcare: will the COVID pandemic worsen non-COVID outcomes and disease outbreaks?. Progress Pediatric Cardiol. 2020.

29. Place R, Lee J, Howell J. Rate of pediatric appendiceal perforation at a children's hospital during the COVID-19 pandemic 
compared with the previous year. JAMA Network Open. 2020;3(12).

30. Ropeik D. Poor risk communication in Japan makes the fear much worse. Psychology Today. 2011

31. Menon KU, Goh KT. Transparency and trust: risk communications and the Singapore experience in managing SARS. J Commun Manag. 2005;9(4):375-83.

32. Granatt M. On trust: using public information and warning partnerships to support the community response to an emergency. $\mathrm{J}$ Commun Manag. 2004;8(4):354-65.

33. Rosenbaum $\mathrm{L}$. The untold toll - the pandemic's effects on patients without covid-19. N Engl J Med. 2020;382(24):2368-71.

34. Malone KG. 'Secondary harm' possible for sick people avoiding ER due to COVID-19. The Canadian Press. April 18, 2020. Accessed Oct 1, 2020.
35. Taylor P. Does an ER visit put me at risk of getting COVID-19? https://healthydebate.ca/personal-health-navigator/risk-covid19er. Published May 1, 2020. Accessed Oct 1, 2020.

36. Mendleson, R. Wheere have all the patients gone during COVID19? Not to the ER. Star analysis reveals stark, nationwide trend. https://www.thestar.com/news/canada/2020/05/23/fear-of-covid19-keeping-canadians-out-of-emergency-rooms-star-analysisshows.html. The Star. Published May23rd, 2020. Accessed Mar 8th, 2021.

37. Is it safe to go to the ER during COVID-19? https://www.cbc.ca/ radio/is-it-safe-to-go-to-the-er-during-covid-19-1.5553011. CBC Radio. Published May 1, 2020. Accessed March 8, 2021.

\section{Authors and Affiliations}

\section{Adrienne L. Davis ${ }^{1}$ (1) - Alia Sunderji ${ }^{1}$ Shashidhar R. Marneni ${ }^{2} \cdot$ Michelle Seiler $^{3}$. Jeanine E. Hall ${ }^{4}$. Cristina Parra Cotanda ${ }^{5}$. Eileen J. Klein ${ }^{6}$. Julie C. Brown ${ }^{6}$. Renana Gelernter ${ }^{7}$. Mark A. Griffiths ${ }^{8}$. Julia Hoeffe ${ }^{9}$. Gianluca Gualco $^{10}$. Ahmed Mater ${ }^{11}$. Sergio Manzano ${ }^{12}$. Graham C. Thompson ${ }^{13}$. Sara Ahmed ${ }^{14}$. Samina Ali ${ }^{15}$. Ran D. Goldman ${ }^{16}$. For the International COVID-19 Parental Attitude Study (COVIPAS) Group}

1 Pediatric Emergency Medicine, Hospital for Sick Children and Department of Pediatrics, University of Toronto, 555 University Ave, Toronto, ON M5G 1X8, Canada

2 Division of Pediatric Emergency Medicine, Children's Medical Center of Dallas, UT Southwestern Medical Center, Dallas, TX, USA

3 Emergency Department, University Children's Hospital Zurich, Zurich, Switzerland

4 Division of Emergency and Transport Medicine, Children's Hospital Los Angeles, USC Keck School of Medicine, Los Angeles, CA, USA

5 Pediatric Emergency Department, Hospital Sant Joan de Déu Barcelona, Barcelona, Spain

6 Seattle Children's Hospital and University of Washington School of Medicine, Seattle, WA, USA

7 Pediatric Emergency Medicine Unit, Shamir Medical Center, and Sackler Faculty of Medicine, Tel Aviv University, Tel Aviv, Israel

8 Division of Pediatric Emergency Medicine, Children's Healthcare of Atlanta, Emory School of Medicine, Atlanta, GA, USA

9 Pediatric Emergency Medicine, Inselspital University Hospital of Bern, Bern, Switzerland
10 Pediatric Emergency Department, Pediatric Institute of Italian Part of Switzerland, Ticino, Switzerland

11 Pediatric Emergency Medicine, Jim Pattison Children's Hospital, University of Saskatchewan, Saskatoon, SK, Canada

12 Department of Pediatric Emergency Medicine, Geneva Children's Hospital, Geneva University Hospitals, and Faculty of Medicine, University of Geneva, Geneva, Switzerland

13 Pediatrics and Emergency Medicine, Alberta Children's Hospital and University of Calgary, Calgary, AB, Canada

14 Department of Emergency Medicine, Mary Bridge Children's Hospital, Tacoma, WA, USA

15 Department of Pediatrics, Faculty of Medicine and Dentistry, Women and Children's Health Research Institute, University of Alberta, Edmonton, AB, Canada

16 The Pediatric Research in Emergency Therapeutics (PRETx) Program, Division of Emergency Medicine, Department of Pediatrics, University of British Columbia, BC Children's Hospital Research Institute, Vancouver, BC, Canada 